\title{
Anônimos supercampeões: a equipe de rafting Bozo D'água e a caracterização dos esportes de aventura
}

\author{
Marília Martins Bandeira' \\ Alexandre Bastos ${ }^{2}$ \\ Sílvia Cristina Franco Amaral ${ }^{3}$
}

\section{RESUMO}

O objetivo deste artigo foi problematizar a caracterização dos esportes de aventura a partir do caso da equipe de rafting Bozo D'água, um contraexemplo em relação à literatura pioneira sobre o tema. Parte de etnografia mais ampla na cidade de Brotas, analisa dez entrevistas cotejadas com observação de campo. Os resultados indicam que, ao contrário da prática de aventura caracterizada como participação não competitiva de lazer, o esporte de alto rendimento foi a alternativa para viabilizar a participação esportiva em atividade de aventura para praticantes de classes baixas. Conclui-se que diferentes formas de apropriação e distintas versões dos esportes de aventura variam conforme contexto e questões de classe e que o potencial das práticas de aventura de colocar em circulação valores esportivos alternativos perde espaço na medida em que as políticas públicas brasileiras priorizam o esporte de alto rendimento.

Palavras-chave: Esportes de aventura. Esportes alternativos. Esportes na natureza.

1 Universidade Federal de Juiz de Fora, campus avançado de Governador Valadares (UFJF-GV). Doutora em Educação Física pela Unicamp. Contato: mariliamartinsbandeira@gmail.com

2 Faculdade de São Sebastião (FASS). Mestre em Educação Física pela Unicamp. Contato: alebastos07@gmail.com

3 Universidade Estadual de Campinas (UNICAMP). Livre-docência pela Faculdade de Educação Física da UNICAMP e pós-doutora pela Universidade de Barcelona. Contato: scfa@fef.unicamp.br

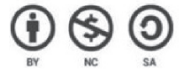

Este texto está publicado sob uma licenca Creative Commons Atribuição NãoComercial-Compartilhalgual - CC BY NC AS

Mais detalhes em: https://br.creativecommons.org/licencas/ 


\title{
Anonim superchampions: Bozo Dágua rafting team and the characterization of adven- ture sports
}

\begin{abstract}
This paper's objective was to analyse the characterization of adventure sports though the analysis of the practice conditions of the Brazilian rafting team called Bozo D 'água, a counterexample regarding the literature review. Part of an ethnography, it is focused on ten in depth interviews and field observation. The results indicate that, on the contrary of the adventure practice described as leisure participation, high performance sport was the only possibility of adventure participation for those athletes. Concluding that different versions of adventure sports vary according to class issues, and the potential for circulating alternative sportive values of the adventure practices lose space as Brazilian public politics prioritize high performance sports.
\end{abstract}

Keywords: Adventure sports. Alternative sports. Nature-based sports.

Anónimos supercampeones: el equipo de rafting Bozo D’agua y la caracterización de los deportes de aventura

\section{RESUMEN}

El objetivo de este artículo fue problematizar la caracterización de los deportes de aventura a partir del caso del equipo de rafting Bozo de agua, un contraejemplo en relación a la revisión de literatura. Parte de una etnografía más amplia, se centra en diez entrevistas en profundidad cotejándolas con la observación de campo. Los resultados indican que, diferentemente de la práctica de aventura caracterizada como participación no competitiva de ocio, el deporte de alto rendimiento fue la alternativa para viabilizar la participación en actividad de aventura para practicantes de clases bajas. Se concluye que diferentes formas de apropiación y distintas versiones de los deportes de aventura varían según contexto y cuestiones de clase y que el potencial de las prácticas de aventura de poner en circulación valores deportivos alternativos pierde espacio en la medida en que las políticas públicas brasileñas priorizan el deporte de alto rendimiento.

Palabras clave: Deportes de aventura. Deportes alternativos. Deportes en la naturaleza. 


\section{INTRODUÇÃO E BASES TEÓRICAS ${ }^{4}$}

Apesar de o montanhismo esportivizado ser tão ou mais antigo que o futebol (DIAS, MELO e ALVES JUNIOR, 2007), o conjunto dos esportes praticados no meio ambiente natural (COSTA, 2000; MARINHO, 2008) foi considerado um fenômeno atual porque popularizado a partir da década de 1960, na medida em que dialogava com preocupações ecológicas e contraculturais contemporâneas (LE BRETON, 1990; COSTA, 2000; RINEHART \& SYDNOR, 2003; WHEATON, 2004; SCHWARTZ, 2006; MARINHO, 2008; PIMENTEL, 2008). Práticas que se renovaram ou foram criadas com equipamentos fabricados com materiais inovadores desenvolvidos nas duas grandes guerras mundiais encontraram condições ainda mais propícias para sua disseminação com as inovações tecnológicas do século XXI (RINEHART e SYDNOR, 2003, p.14). O número crescente de adeptos, a criação de uma mídia digital especializada, mais recentemente, sua ampla inclusão na mídia convencional (RINEHART e SYDNOR, 2003; SPINK, 2008) e sua presença em agendas políticas nacionais (TOMLINSON et al, 2005; BANDEIRA, 2016) afastam as interpretações que viam essas práticas como subversão de poucos ousados e impõe considerá-las como significativas e definitivas para o tempo que vivemos.

Há uma discussão conceitual que trata deste fenômeno caracterizando-o de diferentes maneiras, utilizando termos e interpretações distintas entre si, tais como: esportes californianos (BOURDIEU, 1990), esportes de deslize (POCIELLO, 1995), esportes alternativos (RINEHART e SYDNOR, 2003), esportes radicais (UVINHA, 2001; PEREIRA e ARMBRUST, 2008; SÁ e BRANDÃO, 2009), esportes de estilo de vida (WHEATON, 2004), esportes na natureza (DIAS, MELO e ALVES JR, 2007), entre outros. Cada uma destas expressões apresenta limitações ou ênfases. Por exemplo, esportes californianos serve muito bem para o skate e o windsurfe, mas não remete à origem polinésia do surfe, nem abrange as atividades de montanha. Para solucionar isto, mais abrangentes, não restritas à versão esportiva, foram propostas expressões tais como AFAN - atividades físicas de aventura na natureza - (BETRAN, 2003; SCHWARTZ, 2006), e atividades de aventura (PIMENTEL, 2013) e práticas de aventura (BANDEIRA, 2009; 2012) cabem na consideração destas modalidades na interface com o turismo.

No Brasil, ao longo dos anos, o termo aventura passou a prevalecer depois da criação do Congresso Brasileiro de Atividades de Aventura e da Comissão de Esportes de Aventura, pelo Ministério do Esporte, ambos em 2006. Segundo Bandeira (2016) porque esta expressão enfatiza a presença de riscos específicos da exposição à natureza ou ambientes incontroláveis e da experimentação de máquinas ou arenas esportivas inovadoras criadas para a invenção de gestos e manobras em grande altura, velocidade ou profundidade.

Além disto, apesar de Marinho (2003), Rinehart e Sydnor (2003) e Wheaton (2004) já indicarem que tais práticas estariam passando por um processo intenso de esportivização na virada do século XX para o XXI, referências muito usadas no Brasil como Pociello

4 Agradecemos à Coordenação de Aperfeiçoamento de Pessoal de Nível Superior (Capes) pela bolsa de mestrado da primeira autora que possibilitou esta pesquisa. 
(1995) e Le Breton (2009), afirmavam que este conjunto de práticas corresponde a uma tendência crescente por modalidades individuais, cooperativas, hedonistas, econômicas em esforço, com gestos e regras pouco padronizados, sendo associadas a experiências de liberdade e, portanto, mais associadas ao lazer. Haveria ainda, segundo Le Breton (2009, p. 90), nesses tipos de esportes uma oposição declarada às atividades baseadas no treinamento, na disciplina e na competição e focadas no prazer, pressuposto que ainda embasa muitos estudos brasileiros. Consequentemente, os estudiosos do lazer foram os que mais se dedicaram aos estudos da aventura no Brasil.

Entretanto, segundo Rinehart e Sydnor (2003) e Wheaton (2013), a popularização e apropriação em usos diversos tencionou os significados originais destas práticas. Rinehart e Sydnor (2003) já alertavam que algumas destas modalidades não podiam ser consideradas alternativas visto que um conjunto delas, inaugurado para os X-Games, foi inventado diretamente para a sua transmissão televisiva e competição, ou seja, para a mídia de massa, contendo valores hegemônicos do esporte espetáculo. Já Wheaton (2013), problematiza o fato de tais modalidades serem majoritariamente praticadas pelas elites masculinas e brancas.

No cenário brasileiro, Dias (2007) e Pimentel (2013), em debate conceitual mais filosófico, já relativizaram o enfoque romântico dos estudos pioneiros sobre os potenciais educativos da integração com a natureza e suposta ruptura com a competitividade nas práticas de aventura. Mas, apesar de modalidades tais como o montanhismo, o surfe e o skate terem gozado de investigações monográficas aprofundadas, outras modalidades, como o rafting, por exemplo, não dispõem ainda de muitas investigações de referência. Sousa (2004) e Carnicelli Filho (2005) e Schwartz e Carnicelli Filho, (2006) foram os pioneiros em estudar a modalidade no Brasil. Entretanto, suas abordagens de pesquisa privilegiam a dimensão turística desta modalidade e deixam por desvelar sua faceta esportiva competitiva.

Para colaborar com o preenchimento desta lacuna, o presente artigo traz dados descritivos concretos e aprofundados sobre uma realidade empírica que desmistifica o rafting como prática essencialmente cooperativa, assim como está descrito por Sousa (2004). Em seu estudo de mestrado, a autora afirma que o rafting "tem intencionalidade zero, a não ser a conquista do prazer momentâneo (p.114)". A partir de pesquisa de campo de nove meses de imersão total no mesmo campo de estudo da autora, o presente artigo refuta esta afirmação.

Tendo Sousa (2004), Carnicelli Filho (2005), Schwartz e Carnicelli Filho (2006) e Le Breton (2009) como referências principais, a primeira autora do presente estudo chegou ao campo com a expectativa de investigar valores e concepções de esporte alternativos aos convencionais, mas se surpreendeu com um ambiente altamente regrado e competitivo. Portanto, o objetivo geral do presente artigo é analisar o rafting brotense em suas contribuições para a caracterização do conjunto das práticas de aventura.

Diferentemente do que preconiza Le Breton (2009) para o conjunto dos esportes radicais ou de aventura, no caso da equipe Bozo D'água, doze vezes campeã brasileira e hexacampeã mundial (em 2016), feitos desconhecidos da maioria da população brasileira, o esporte de aventura é competitivo, vivido em equipe, de alto rendimento, altamente 
disciplinado, centrado em força, esforço e padronização dos gestos esportivos. O que sinaliza para a pluralidade de apropriações possíveis de uma prática de aventura e importância de não ocultar esta complexidade em sua definição.

\section{Materiais e Métodos}

Este artigo deriva de um estudo etnográfico mais amplo, que teve como objetivo geral compreender o significado da noção de aventura na prática esportiva. Etnografia concebida como a análise descritiva detalhada de um fenômeno social a partir dos pontos de vista daqueles que o vivem (GEERTZ, 1989; CLIFFORD, 2002). Metodologia que demandou convivência duradoura com os pesquisados e o cruzamento de diversas técnicas de pesquisa, conforme foram aceitas no contexto estudado. Para uma imersão total, ou seja, conviver o máximo possível com os pesquisados, a primeira autora escolheu como recorte e campo de pesquisa a cidade autointitulada "Capital Brasileira da Aventura", Brotas, no estado de São Paulo. E foi morar lá por nove meses de observação direta e participante diariamente nas rotinas de trabalho, treinamento e lazer de diversos autodenominados aventureiros, atletas de aventura e/ou profissionais de turismo de aventura, muitos dos quais compunham a equipe Bozo D'água, ou equipes associadas a ela. O que proporcionou o acompanhamento dos campeonatos brasileiros de rafting de 2010 e 2012 presencialmente e manutenção do contato com estes atletas nos anos subsequentes via mídias sociais e análise de notícias sobre os campeonatos brasileiros e mundiais, publicadas no site da Confederação Brasileira de Canoagem (CBCa) e mídia especializada.

Durante a pesquisa de campo, o rafting se destacava como carro chefe do turismo em Brotas, já que muitos rios brasileiros têm períodos de seca que não possibilitam navegação, enquanto o rio Jacaré- Pepira-Mirim (carinhosamente chamado de Jacaré), no entorno do qual cresceu o município, permite navegação mesmo na baixa temporada de chuvas, o que é considerado em termos nativos "um rio constante".

Além disto, o rafting em Brotas também era considerado pelos interlocutores desta pesquisa como "o melhor rafting do mundo", no sentido de ter os melhores rafteiros do mundo, já que uma equipe adulta masculina da cidade era, em 2016, doze vezes campeã brasileira, invicta há uma década, sagrando-se hexacampeã mundial. Além disto, as equipes adulta feminina, chamada Brotas 40 graus, junior masculina chamada Alaya Competition e a junior feminina, chamada Meninas do Rio, ocupavam também as mais altas posições nos pódios nacionais e internacionais (nomes das equipes e sua conformação podem mudar conforme os arranjos de apoios e patrocínios que são galgados a cada ciclo competitivo).

Em Brotas, o rafting, não só era atividade mais procurada pelos visitantes, como a melhor remunerada e valorizada socialmente. Nestas ocasiões, além de outras 25 entrevistas com aventureiros de perfis diversos, foram realizadas dez entrevistas com os atletas que compõem a Bozo D água, recorte específico deste texto. Todas as entrevistas foram consentidas seguindo prescrições éticas da resolução 466/12 do Conselho Nacional de Saúde, gravadas em áudio e suas citações literais identificadas por números para proteger a privacidade dos autodenominados "rafteiros". 
As entrevistas conduzidas foram abertas com o intuito de produzir narrativas de trajetórias de vida, já que questionamentos conceituais mais objetivos foram testados em abordagem piloto e não se mostraram encorajadores para os participantes, que se sentiam incapazes de responder. Duas perguntas principais foram, então, elaboradas de forma a estimular respostas sobre as experiências pessoais dos sujeitos e simultaneamente garantir a manutenção do foco no tema da pesquisa: "Para você o que é aventura?" e "Como você se interessou por aventura e começou a praticar?". A partir destas perguntas outros questionamentos espontâneos foram formulados com o intuito de esclarecer ou detalhar o que fora sendo relatado. A análise dos dados foi realizada de forma interpretativa, dialética e crítica, confrontando as vivências e preocupações mais frequentes entre os pesquisados, com as questões investigadas pela literatura científica sobre o tema.

O objetivo específico do presente artigo é, portanto, problematizar as condições de prática destes atletas e como desafiam as definições de esportes de aventura contidas na literatura pioneira. Além disto, em um contexto em que, mesmo com a conquista do hexacampeonato mundial nos Emirados Árabes em 2016, a população brasileira em geral não conhece a Bozo D'água e a equipe ainda carece de apoio, os seus membros nos pediram para não ocultar o nome da equipe e divulga-la.

\section{Resultados e discussão}

Observando as rotinas na margem do rio Jacaré, eram ouvidas narrativas sobre brincadeiras das crianças brotenses no rio, como a natação, a pesca, os saltos e a fruição das corredeiras sobre tábuas de madeira, e quaisquer outros materiais de flutuação, culminando com o uso de câmaras de ar de pneus de caminhão no que se convencionou chamar "descer o rio de bóia". Deslizar com a correnteza transpondo trechos pedregosos se tornou divertimento local, foi incorporado à identidade brotense e passou a ser caracterizado como prática nativa: “A maioria dos meninos da cidade brincam de bóia porque é de graça, o trecho é fácil de chegar, dá pra ir andando, e acaba aqui na ponte do centro da cidade" ("RAFTEIRO" 1).

Outra narrativa bem conhecida e compartilhada por diversos brotenses, contada em diversas entrevistas, é aquela sobre a época pós-Eco-Rio-92, Conferência das Nações Unidas sobre o Meio Ambiente e o Desenvolvimento, que aconteceu no Rio de Janeiro em 1992. Brotas, em dificuldades econômicas, teria sido abordada por um curtume, mas optou pela sua não instalação. O movimento ambientalista Rio Vivo, em substituição à atividade poluidora, sugeriu à prefeitura a implantação do ecoturismo. A visitação à cidade para banhos de cachoeira se intensificou, a "descida de bóia" foi demandada como passeio e batizada de bóiacross, para atender os interessados em vivenciar uma "típica" experiência de Brotas.

Nesse contexto, segundo entrevistas com os empreendores de aventura pioneiros da cidade, teriam se formado as primeiras agências turísticas e os adeptos do "bóiacross", em sua maioria com escolaridade correspondente ao ensino médio, por vezes incompleto, 
em busca de melhores trabalhos que a colheita de cana e laranja e a construção civil, tornaram-se "guias de bóia". A concorrência levou os empreendedores a importarem atividades para diversificar seu leque de serviços. A condição geográfica possibilitou que o cachoeirismo, o canioning e o rafting chegassem à cidade.

Segundo o site da Confederação Brasileira de Canoagem (CBCa), o primeiro registro de descida de rafting no mundo data de 1869, quando Wesley Powel - um dos expedicionários mais conceituados da história americana - organizou uma expedição no rio Colorado / EUA, em barcos de madeira com remo central. Ainda segundo a CBCa, o rafting com finalidade comercial foi realizado somente em 1909 pela Julio's Stone's Grand Canyon, mas os botes ainda eram rígidos, de madeira. Os primeiros botes infláveis foram criados nos EUA, em 1936, popularizando-se a partir de 1980 com o surgimento do bote "self bailer", confeccionado com materiais mais leves e resistentes.

Ainda de acordo com o website da CBCa, o rafting chegou ao Brasil em 1982, através da empresa TY-Y Expedições, cujas descidas se restringiam ao rio Paraíba do Sul e rio Paraibuna, ambos em Três Rios (RJ), em um bote para dez pessoas com remos centrais operados pelo guia. Neste período passou praticamente despercebido pelos brasileiros, pois toda a programação foi desenvolvida para atender exclusivamente aos turistas estrangeiros em férias no Rio de Janeiro. Com a inovação tecnológica, o rafting se estabeleceu no Brasil a partir de 1990 com a criação da empresa Canoar Rafting \& Expedições que operava com bote para seis pessoas e remos individuais.

A Canoar, empresa de um professor de educação física e técnico da delegação brasileira de canoagem dos Jogos Olímpicos de Barcelona, que conheceu o rafting em viagens internacionais, é mencionada pelos habitantes de Brotas como a primeira a comercializá-lo em sua cidade, depois de se instalar no rio Juquiá, em Juquitiba. Seu fundador, reconhecido canoísta e técnico da seleção brasileira de canoagem, conta que recebia pedidos de leigos que desejam ser levados a passeios em rios e que conhecendo o rafting em viagem internacional enxergou o potencial da embarcação, por poder levar um grupo sozinho. Neste contexto ele formou os primeiros profissionais do rafting brasileiro assim como conhecemos hoje, que posteriormente teriam iniciado os "guias de bóia" nativos de Brotas na modalidade. Estes últimos contam que o almejavam como lazer e esporte, mas descobriam na demanda do rafting de condução como serviço sua possibilidade de acesso à modalidade.

Além do rafting de expedição, a Canoar promovia competições de rafting entre seus instrutores e clientes mais assíduos. Assim, teriam se formado as primeiras equipes competitivas locais de rafting, em sua maioria correspondentes à agência turística de atuação de seus membros. Outro polo de rafting se estabeleceu em Três Coroas, no Rio Grande do Sul, e um calendário de competições se regularizou via incorporação do rafting pela Confederação Brasileira de Canoagem (CBCa), que em seu site oficial o define, corroborando a descrição de Sousa (2004), assim:

O Rafting consiste na descida de rios em botes infláveis. Os integrantes da embarcação remam sob o comando de um Instrutor, responsável pela orientação do grupo 
durante o percurso. A prática do Rafting implica conceitos muito importantes no relacionamento entre as pessoas, como solidariedade, união, liderança, trabalho em equipe e percepção sensorial (Disponível em: http://www.canoagem.org.br/pagina/ index/nome/rafting/id/120).

Surpreendentemente, esta definição oficial da entidade de representação esportiva máxima no país está centrada no rafting turístico, o que não corresponde com a realidade da prática esportiva competitiva, que é a que o órgão regula, O que indica a falta de atenção que a modalidade recebe dentro da CBCa em comparação a outras modalidades de canoagem. Para justificar esta crítica, é importante aqui descrever as competições de rafting acompanhadas durante esta pesquisa, que ocorrem segundo normas da Federação Internacional de Rafting e da própria CBCa.

Um campeonato oficial de rafting consiste em disputas de navegação em botes infláveis por equipes de seis (R6) ou quatro (R4) pessoas. O campeonato é dividido em provas obrigatórias em quatro disciplinas, dispostas necessariamente na ordem: tiro, sprint paralelo, slalom e descenso ou descida, em inglês chamadas: sprint, head to head ou $\mathrm{H} 2 \mathrm{H}$, slalom e downriver. O tiro consiste na descida de um trecho de corredeira do rio que tenha entre um a três minutos, no menor tempo possível. A ordem de descida é determinada por sorteio. O sprint paralelo é realizado usualmente o mesmo trecho do tiro, em que se possa realizar o scout (observação e avaliação das corredeiras pela margem). No sprint paralelo, a largada é realizada sempre com dois botes lado a lado, com condições iguais de performance tanto quanto possível. A ordem de equipes que competirão entre si pode ser determinada pela classificação do tiro ou pela ordem do menor ao maior tempo de descida em uma bateria de uma equipe por vez que precede a primeira bateria de duas equipes, combinando a equipe de melhor tempo com a de pior, a segunda com a penúltima e assim sucessivamente. A equipe mais rápida da bateria precedente sempre terá a escolha da linha de largada. A prova seguinte é o slalom, que é a prova de agilidade e controle do bote entre balizas. Cada prova deve ter no mínimo oito e no máximo quatorze balizas distribuídas igualmente para a direita e a esquerda, com no mínimo duas e no máximo seis contra a correnteza. As que devem ser passadas no sentido da correnteza devem ser preferencialmente pintadas em verde e branco e aquelas contra a correnteza devem ser pintadas preferencialmente em vermelho e branco. Cada duas balizas próximas formam o que se chama de porta, que deve ter uma largura mínima de $2.50 \mathrm{~m}$ e um número. A passagem pelas portas deve ser realizada na ordem de sua numeração. Uma passagem será considerada correta se todos os membros da equipe estiverem no bote e suas cabeças passarem entre as balizas. O objetivo nesta prova é fazer todas as passagens no menor tempo possível. Se algo não estiver em acordo com as regras da prova, penalidades em tempo são adicionadas ao tempo de execução da prova (por exemplo, toque na baliza = 5 segundos, uma ou mais pessoas não passarem a cabeça por entre a porta $=50$ segundos, passar pela porta no sentido errado $=50$ segundos, etc). A última prova de um campeonato é o descenso (ou descida), que dura entre 20 e 60 minutos dependendo das corredeiras e do acesso ao rio. O objetivo nesta prova é realizar o percurso antes das demais equipes, 
além de ser uma prova de resistência física. A largada acontece em grupos entre 4 e 8 botes, dependendo da situação do rio. Preferência dada para o maior número de botes por vez. As equipes podem selecionar sua posição de início de acordo com os pontos conseguidos anteriormente, do mais pontuado até o menos pontuado, ordem de largada também obedece a este critério. Assim como no slalom, punições em tempo podem ser acrescentadas ao tempo final de prova. Para definir o ganhador da competição, o sistema de pontuação das provas soma 1.000 pontos. O ganhador é aquele que obtém o maior número de pontos, mas os ganhadores de cada uma das provas também são celebrados. O tiro vale 100 pontos. O sprint vale 200 pontos. O slalom vale 300 pontos. E a descida ou descenso vale 400 pontos. O vencedor é aquele que acumula a maior quantidade de pontos na soma das quatro provas.

Pode-se perceber, então, que Sousa (2004) não diferenciava em seu trabalho o rafting turístico do rafting esportivo, e também, alertamos aqui, como em Bandeira e Ribeiro (2015) sobre a necessidade de diferenciar o rafting esportivo expedicionário (no qual uma equipe explora livremente corredeiras diversas) do rafting esportivo competitivo no qual o rendimento de equipes diferentes é comparado para ranqueamento, sendo que em algumas provas diversas equipes diferentes podem estar no rio ao mesmo tempo disputando posições de forma que até pode haver colisão de remos e braços e empurrões propositais, o que relativiza a "solidariedade" das definições da CBCa e de Sousa (2004).

De volta à narrativa cronológica sobre Brotas, a equipe Canoar tornou-se tricampeã brasileira e a primeira a participar em um campeonato mundial. Anos depois, brotenses inspirados pela Canoar, crescidos na bóia e formados no rafting como ofício, convidaram três guias da Canoar para formar a equipe Bozo D'água, que superou sua hegemonia, auxiliando na estruturação de seis outras equipes (adultas e juniores, masculinas e femininas). Entretanto, apesar do número de atletas interessados, a caracterização pela falta (de equipamentos, verba, estrutura e apoio) é como seus membros a apresentam. O "rafteiro" 1 , condutor de rafting, criador, técnico e capitão, conta como este nome foi atribuído à equipe:

\footnotetext{
Naquela época nós era tudo mais novo, tudo mulecaço. Era brincalhão, não tinha tanta seriedade. E devido a gente não ter os equipamentos, era emprestado, cada um com capacete de uma cor, colorido, colete, cada um com a sua lycra, a gente ficava parecendo assim uns palhaços nas competições, sempre alegres, coloridos e brincando, né? Que a gente gosta de ser alegre. E aí nós tinha que inventar um nome e lembrou do palhaço Bozo e pensamos que pôr alguma coisa que tivesse água era bom, e foi assim.
}

Apesar da descontração e da alegria, como elementos estruturantes da equipe, que também aparecem nas análises de Sousa (2004) e Schwartz e Carnicelli (2006), no convívio mais duradouro, detalhes sobre a escolha por ser atleta (a seguir) trazem à tona um discurso informado pela concepção de esporte de caráter funcionalista. Nota-se também a exaltação de uma moral atleta como sinônimo de bom caráter. Contraditoriamente, a escolha esportiva é reforçada pela moralidade local, mas sobrevive de incentivos materiais 
escassos. A fala a seguir corrobora com Bracht (2005), para quem: "quase não nos damos conta de como 'ser esportivo' nos é socialmente solicitado" (p. 113):

\begin{abstract}
Quem é atleta já faz um bem pra ele, porque um atleta geralmente não bebe, não fuma, não vai estar arrumando confusão, então, já é um bem pra sociedade, você aprende a conviver em sociedade porque você tá sempre com a equipe, aprende a respeitar, aprende a ter limite, aprende a ser disciplinado e se você não tá fazendo mal pra ninguém, você só tá fazendo o bem, porque você tá fazendo bem pra si próprio, tendo saúde, tendo disciplina [...] Se você é atleta você tem mais limites, sabe o que pode e o que não pode, por isso eu acho que isso devia fazer a gente merecer o apoio das pessoas e a oportunidade de continuar fazendo o que a gente gosta. Mas ninguém vai falar assim: "eu vou te registrar, você vai trabalhar aqui comigo e quando for época de campeonato eu te libero pra viajar". Se a gente tivesse esse apoio, se as pessoas dessem esse reconhecimento, facilitava. Mas ninguém diz: "como você é bicampeão mundial, vou arrumar um serviço que dê pra deixar você treinar todo dia". Por isso que a gente não consegue ter carteira assinada também, se bem que aqui muito pouca gente assina, por isso que a gente queria que o esporte fosse profissional ("RAFTEIRO" 1).
\end{abstract}

Este depoimento mostra a necessidade de atrelar a prática do rafting ao momento de trabalho, visto que outros ofícios não permitem tal atividade paralela. Segundo o entrevistado, o devir esportista é idealmente bem avaliado, mas tornar-se atleta recebe incentivo apenas retórico, pouco operacionalizado tanto pelo poder público, quanto pela iniciativa privada. E a solução para esse perfil de esportistas seria o esporte profissional de espetáculo:

Eu queria ser atleta, né? Como todo menino, queria jogar bola, mas na minha época o futebol aqui já era muito mercenário. Não era só uma questão de jogar bem. Era uma questão de ter dinheiro. Se tinha agente, ficava. Se não, já era. Aí eu vi que futebol não ia dar, porque eu não tinha dinheiro. E como eu já trabalhava com o rafting, quando o pessoal começou a sair pra competição eu vi ali a oportunidade de ser atleta, né? Em 1998, 1999, eu tinha dezessete anos e a escola trouxe nós pra fazer uma descida. Eu tinha um amigo que já trabalhava e tava precisando de condutor. Na minha primeira descida trabalhando [...] eu já peguei o rio cheio, mas acabei me saindo bem. E aí já me contrataram e eu fui aperfeiçoando na prática, eu já tinha o conhecimento de descer de bóia, [...] pra brincar, então, eu já tinha a ideia. Aí, em três meses no máximo, teve o primeiro campeonato aqui em Brotas e me convidaram pra remar. Depois eu fui pro brasileiro que foi em Piraju. Em 2000 eu já fui remar em outra equipe. E aí em 2002 eu montei a Bozo D’água pra gente remar em Apiúna, Santa Catarina, porque as duas outras equipes de antes tinham desmanchado e eu gostava de competir ("RAFTEIRO" 1).

Este excerto ilustra, como Bourdieu (1983) preconiza em sua teoria, que agentes sociais distintos significam diferentemente as mesmas práticas. No contexto deste estudo, o futebol, convencionalmente visto como prática popular, é que é operador de exclusão. A fala do entrevistado mostra que o acesso ao futebol de alto nível não é impedido apenas pela performance, mas pela condição financeira. E o rafting, não obstante as dificuldades a seguir apresentadas, muito relacionadas à careza dos equipamentos, é vivido em Brotas como a modalidade que possibilitou criar estratégias de participação esportiva. 
Seu caráter ainda pouco profissional proporcionou um acesso mais livre à modalidade. Por ser uma prática ainda em consolidação, diferentemente do futebol que já está estruturado em formato piramidal de alto rendimento (BRACHT, 2005), a adesão se dava por vias mais difusas, como conta o "rafteiro" 2 :

Em 2003, o [1] me chamou pra montar a Bozo D'água e a gente ganhou o brasileiro. Antes, qualquer equipe que se inscrevia podia ir pro mundial, mas por coincidência foi a primeira vez que o campeonato nacional valia a única vaga pro mundial e a gente foi. Então, eu realizei dois sonhos logo no primeiro ano, ganhei o brasileiro e ia pro mundial. Só que a gente não tinha dinheiro, não tinha nada, não tinha apoio. E a gente sabia remar do nosso jeito, não tinha nenhuma técnica. Aí a gente foi pedir ajuda pros caras que já tinham ido pro mundial, que eram mais experientes e falamos: - Dá uns toques aí pra gente. E aí o cara vira e fala: - A gente cobra quatrocentos reais por pessoa pra dar curso. Aí a gente: - Muito obrigado, mas a gente vai no que a gente sabe. $E$ foi no que a gente tinha, que era força. $E$ no nosso primeiro mundial a gente já ficou em terceiro, que tinha sido a melhor colocação do Brasil em toda a história, mas contamos com a sorte.

Note-se, nestes trechos de entrevista, já dois pontos que diferem da revisão bibliográfica: a exaltação da equipe e da convivência, em oposição à caracterização dos esportes de aventura como individuais e a necessidade da força em oposição à leveza tecnológica. Mas, havia apenas um cargo administrativo designado ao rafting na $\mathrm{CBCa}$, os atletas ressentiam-se por sentirem-se deixados de lado em comparação à canoagem olímpica e as competições aconteciam em situação precária, viabilizadas pelas prefeituras-sede e esforços individuais de entusiastas, como constatado nas observações dos campeonatos brasileiros de 2010 e 2012. Neste princípio, a tímida premiação do campeonato brasileiro era usada para pagar uma pequena parte dos custos do campeonato mundial subsequente.

Além disso, assim como está apresentado por este campo de pesquisa, interessar-se por ser atleta não está relacionado à conquista de tempo livre numa sociedade que liberaria cada vez mais das tramas do trabalho, mas a jornadas adicionais de trabalho para viabilizar o esporte. Nesse contexto, turismo e esporte viabilizam um ao outro:

No nosso primeiro brasileiro, a gente nem tinha equipamento, cada um foi com o que tinha, bote emprestado, remos usados, remendados. Mas, no último dia, o cara da Hidro, disse que se a gente fosse pro mundial ele ia nos apoiar. Então, pro mundial a gente já foi com colete e capacete dele. Aí, em 2005, a gente perdeu o brasileiro pra uma equipe do sul e perdeu a vaga pro mundial e os apoios. Eu fiquei desanimado e fui guiar no Jalapão, fiquei lá cinco meses. Aí o [5] me falou de ir pro Panamericano na Costa Rica, que a gente ganhou em 2006. Por isso, a Zefir nos deu um bote. $\mathrm{E}$ aí, quando as agências tinham mais clientes do que bote, a gente alugava o nosso pra elas e foi juntando um dinheiro pra comprar outros botes e alugar e outras equipes que se espelhavam e treinavam com a gente podiam usar. A gente ganhou o brasileiro de novo em Juquitiba. Em 2007, o brasileiro foi em Brotas e valia vaga pro mundial. As pessoas da cidade e o prefeito na época, que sempre acreditou e financiou nosso transporte para as competições, por ver mais de perto, se animaram mais. Então, a gente pensou: - Não podemos deixar passar essa oportunidade! A gente treinou muito e ganhou o nosso primeiro mundial. Mas, mudou a 


\begin{abstract}
gestão e a nova prefeitura demorou. O pessoal não aguentava mais a gente pedindo ajuda. As pessoas pensavam: - A gente vai dar dinheiro pra esses moleques irem passear, brincar? Aí um amigo: - Em vez de vocês andarem por aí pedindo, vocês tinham que oferecer alguma coisa em troca. Aí, começamos rifando coisas. E outro: - Vou fazer um logo pra vocês colocarem numa camisa e não vou cobrar nada. Vocês vendem a camisa e também promovem a equipe. Mas depois de tempo, o pessoal da cidade não aguentava mais comprar camisa, sobrava quarenta camisas e tinha que pagar do bolso. Aí, a gente percebeu que vendia melhor pra turista. Então, a gente começou a mostrar no ônibus que leva pro rafting e explicar pro pessoal que que era uma lembrança e ao mesmo tempo que ia ajudar a gente a ser os melhores do mundo. Que a gente não queria ser só mais um guia, que a gente queria trazer isso pro país e pra eles. Aí que a gente cismou que tinha que ganhar esse mundial pra provar pro povo que ajudava que a gente não ia passear, nem brincar, que era sério. Aí a gente voltou com o título ("RAFTEIRO” 2).
\end{abstract}

De maneira oposta ao que Stigger (2002, p.84) encontrou em sua etnografia, neste caso era desejado o tratamento do esporte federado, oficial e profissional e dinheiro e prestígio eram esperados como parte deste jogo. Embora a brincadeira empreste alguma graça ao nome da equipe, o envolvimento cada vez mais sério com o rafting é sua marca. O prazer esportivo, para esses atletas, está no pódio e não somente na fruição dos rios, pois é o pódio que o viabiliza e mantém. E a representação nacional aparece como conversor do feito da equipe em feito de toda a nação. Dessa forma, com a responsabilidade da representação, o apoio ou financiamento das atividades da equipe por quem não tem diretamente conexão com ela, passa a fazer sentido. Mas, neste caso, o altíssimo rendimento não garante estabilidade financeira.

Em agosto de 2011, a equipe Bozo D’água, na época bicampeã mundial e tetracampeã da copa européia de rafting, conquistou o octacampeonato brasileiro na modalidade e se classificou para o campeonato mundial na Costa Rica. Nesse mesmo ano, a prefeitura de Brotas passou a usar o slogan: "Brotas: o melhor rafting do mundo", mas paradoxalmente a equipe perdeu seu maior patrocinador, que justificou a não renovação do acordo por decidir focar a canoagem olímpica.

Neste processo de galgar reconhecimento para o rafting, uma professora do departamento de Educação Física de Universidade Federal próxima, voluntariamente passou a orientar os atletas em termos de treinamento, alimentação e prevenção de lesões e acompanhá-los nos campeonatos como preparadora física. Com o aniversário de dez anos da equipe, em 2012, estratégias para sua continuação e melhoria de suas condições de existência foram pensadas. Entre elas, a professora sugeriu a criação da Associação Brotense de Esportes Aquáticos, assim como narra o "rafteiro" 3:

A gente fez a ABEA [Associação Brotense de Esportes Aquáticos] pra arrecadar verbas pra ajudar nossa equipe, pra escolinha e pra organizar campeonatos pro pessoal que tá começando. Só que a gente só pode ter recurso do governo e de empresas depois de dois anos. Por enquanto é os atletas e pais das crianças os associados, né? A gente cobra por ano dez reais, mais pra poder ter algum equipamento pra dar treino. E aí a gente espera que a prefeitura entre com recurso pra poder remunerar o 


\begin{abstract}
pessoal que sempre teve ajudando, no caso o [1], né? Porque a ideia da escolinha e correr atrás da associação é [são] dele e ele tem trabalhado de graça com instrução e treinamento [...] O mais certo é isso, né? Porque é ele que dá aula. A gente só dá uma ajuda, de vez em quando, a arrumar as coisas pra levar os pequenos pro campeonato. Mas quem dá aula todo dia é ele. E a gente registrou como local provisório da associação ali o barracão de equipamentos do fundo da agência. O dono cedeu esse uso por um tempo. Mas, a gente espera que depois a prefeitura articule um barracão pra gente guardar o equipamento e ter um telefone.
\end{abstract}

A prefeitura não cedeu aos pedidos da ABEA e o acordo com o dono da agência terminou. Mas outra sugestão da professora para manter a equipe teria sido pleitear a Bolsa-Atleta. Aqueles que conseguiram bolsa-atleta dividiram o aluguel de uma casa para sede da ABEA, próxima ao trecho urbano do rio onde acontecem os treinos diários, e onde foram realizadas algumas provas do campeonato brasileiro de 2012. Assistindo a essas provas, ouviam-se membros de duas equipes de fora da cidade conversando em defesa do esporte amador. Reprovavam a postura das equipes "Bozo", dizendo não querer que seus juniores fossem instigados a tanta competitividade. Em oposição, elogiavam-se ao dizer que faziam o esporte por amor, por divertimento e pela participação e não pela vitória ou bolsa-atleta. Essas pessoas não consideravam que a forma de participação possível dessa parcela da população de Brotas no rafting e no cenário da aventura é via relações de trabalho, contexto em que o desempenho é fundamental. Na base da questão do profissionalismo/amadorismo está presente o conflito social básico da sociedade capitalista. As classes dominantes (burguesia e aristocracia) fizeram da apologia ao amadorismo uma estratégia de distinção social, travestida de atividade realizada pelo simples prazer de realizá-la, sem fins úteis, desinteressada (BRACHT, 2005, p.100).

Archetti (2001), de maneira semelhante, mostra as tensões do polo argentino, quando empregados da lida com os cavalos passaram a ter melhor desempenho que os empregadores que lhes apresentaram tal jogo. As fronteiras entre "rafteiros esportistas amadores empreendedores forasteiros" e seus empregados são subvertidas no melhor ranqueamento de competidores que são treinados não nas viagens de lazer internacionais, mas como trabalhadores braçais do turismo de aventura no interior do Brasil. Para os últimos, as pequenas mudanças promovidas pelas vitórias, embora reclamadas como insuficientes, operam como distinção. Dado que corrobora com Bourdieu (1983, p. 147), quando analisa a relação da prática esportiva com o âmbito do trabalho:

Para compreender disposições tão afastadas do sentido da gratuidade e do fair play das origens, devemos ter presente, entre outras coisas, o fato de a carreira esportiva, que se encontra praticamente excluída do campo das trajetórias admissíveis para uma criança de origem burguesa [...], representar uma das únicas vias de ascensão social para as crianças provenientes das classes dominadas.

Adicionalmente, as entrevistas com os adolescentes recém inscritos na escolinha de rafting revelavam como motivação para a participação no rafting esportivo a impossibilidade de conhecer outros rios apenas com o rafting de lazer, ou seja, o de expedição, já 
que, eles contavam que não tinham recurso para pagar o condutor das agências turísticas sempre que quisessem fazer rafting e porque havia um pedágio muito caro que isolava a cidade de outros rios navegáveis próximos e a maioria dos esportistas que também eram guias turísticos de rafting não tinham carro, o que dificultava o transporte do bote. Não fosse a justificativa da representação da cidade ou do país, não haveria recurso para viabilizar esta circulação entre ambientes naturais diversos tão desejada no imaginário da aventura contemporânea.

Rinehart e Sydnor (2003) já ponderavam a respeito da importância da viagem nestes tipos de práticas, ao considerá-las um tipo de ostentação praticado pelas elites quando da procura de ambientes exóticos os mais exclusivos possível. Além disto, os autores relativizam a suposta quebra com o sistema de representação nacional na prática esportiva, para além da ideia de que estes esportes promovem livre circulação mundial de praticantes não competitivos, como afirmam Sá e Brandão (2009) ou, no caso competitivo, de algumas modalidades, como a corrida de aventura, por exemplo, que são praticadas por equipes que podem ser compostas por membros de diferentes países, ao lembrarem que gênero, cor e classe social afetam diretamente o acesso, ou as possibilidades e condições de viajar e adquirir equipamentos esportivos de tecnologia avançada.

Mas, para além do financeiro, o aspecto simbólico sustenta a dinâmica do rafting brotense. É o pertencimento à aventura em Brotas, assim como o pertencimento ao gym do gueto de Wacquant (2002), que permite que a pessoa se destaque e atraia admiração e aprovação da comunidade local. De maneira semelhante a como os pugilistas saboreiam pertencer a uma pequena confraria reputada por sua bravura física e por sua rudeza, esses "rafteiros" se diferenciam por sua força física e coragem de navegar rios de corredeira. Veem-se impelidos a forjar um corpo mais forte que a falta: a falta de equipamentos, de estrutura, de apoio, de dinheiro. Embora a falta não exclua a vitória e as alternativas criativas que desenvolveram para conquistá-la, além das vaquinhas, rifas, vendas de camisetas e jantares, e aluguel de botes, a dor das múltiplas lesões engolida com o choro.

Além de destaque entre os jovens da comunidade local, o alto rendimento também se converteu em mecanismo de distinção entre guias/condutores de turismo de aventura e forma de garantir sua permanência em um mercado, por vezes, saturado. Enquanto a maioria dos participantes da equipe Bozo D'água trabalhava em uma mesma agência, que usava suas imagens e troféus para publicidade junto aos turistas, eles recebiam quinze reais a mais em relação aos outros guias ou condutores por descida (ato de navegar um trecho de rio na direção da nascente para a foz, neste caso, conduzindo turistas). Ou seja, se um condutor de rafting recebia, como na época, $\mathrm{R} \$ 50$ por descida, aquele que era membro da Bozo D'água recebia $\mathrm{R} \$ 65$ (em um bote com seis turistas, cada um pagava $\mathrm{R} \$ 85$ pelo passeio).

Além disso, isenção de mensalidade em escola de inglês e academia de musculação foram concedidas em troca de divulgação destas empresas nos uniformes, após a vitória no mundial. Mas esses arranjos são muito frágeis e podem mudar a qualquer momento, visto que são informais. Assim que o trabalho de campo na cidade de Brotas foi finalizado esta configuração se desfez e os integrantes da equipe se espalharam na coordenação do 
rafting de agências variadas. Mesmo com uma série impressionante de vitórias conquistadas com pouquíssimos recursos, uma narrativa dramática que poderia soar apelativa à mídia, a Bozo D’água ainda não alcançava o reconhecimento nacional que almejava, já que não apenas eram os melhores da cidade, do estado e do país, mas ganhavam também mundiais, o tetracampeonato mundial conquistado em Foz do Iguaçu, em 2014. O "rafteiro" 3 elucida esta questão:

O esporte cresce em Brotas, mas nacionalmente deu uma parada. A gente tá tentando entender por quê. Antigamente, tinham dezesseis equipes masculinas adultas no campeonato brasileiro. Mas as equipes antigas deixaram de competir, acho que porque a sequência de vitórias da Bozo D'água é muito grande. São muitos anos invictos. E como é amador no Brasil, infelizmente eles não treinam direito, porque têm que trabalhar em outras coisas. E é nítido quem treina e quem não treina. Você vê, os nossos meninos junior nesse campeonato fizeram o segundo melhor tempo da competição na primeira prova. Ou seja, como eles treinam sempre, eles fizeram melhor tempo que as equipes adultas, menos a Bozo D'água. Eu acho que é importante na sua pesquisa você analisar a dificuldade de patrocínio pra esse determinado esporte. Por que a canoa havaiana tem um crescimento enorme? Eu penso que é porque ela tá crescendo em grandes centros como São Paulo e Rio, porque pode ser praticada em água parada, mas o grande problema é a mídia. Como a gente tem estado sempre no topo, parece que não veem novidade nisso, não veem renovação, mas isso não é verdade. Tem muito trabalho aqui! É um projeto muito grande! É oportunidade de esses meninos conhecerem o mundo! Agora a gente tem um campeonato mundial junior e entendeu a importância disso pra continuação do esporte. Nossos moleques já são campeões mundiais. E mais que isso, já sabem a importância de defender nosso Brasil. De dizer: - Eu sou seleção brasileira! E o esporte resgata a criança da rua, da droga. Dá lazer, mas dá disciplina. Ensina a ter objetivos e planejar pra conquistar, ensina a vencer e perder, que são as dificuldades da vida. E também dá cultura, os países que você vai conhecer e as línguas que vai ter que aprender na marra [...] A minha vida mudou. Ela é uma coisa antes e outra depois da Bozo D'água. Por isso, esse ano, a gente já colocou as categorias mirim e fraldinha no campeonato brasileiro, entendeu?

O discurso redentor do esporte (supostamente promotor de saúde, disciplina, caráter, desenvolvimento pessoal e ascensão social) que perpassa essa fala vem atrelado à hegemonia do esporte espetáculo como modelo priorizado pelas políticas públicas brasileiras e revela seu fracasso sem a exposição midiática. Procurando responder a pergunta deste interlocutor durante sua participação na pesquisa, além da questão sobre a maior disponibilidade de "águas paradas" nas capitais (diante da especificidade do rio de corredeira que é considerado adequado ao rafting), outra hipótese não excludente é o nível de risco que cada modalidade oferece e o quanto é apelativo aos iniciantes. A canoa havaiana seria menos arriscada, pois há menos possibilidade de chocar-se com pedras durante a navegação e queda da embarcação.

Além disto, há a complexidade da estrutura dos campeonatos, composto por quatro provas diferentes, demanda diversos dias de duração, e pode ser realizado em trechos diferentes de um rio, o que pode dificultar a formação de uma audiência e de transmissão. 
Embora esta condição esteja sendo superada pelo uso de câmeras portáteis cada vez mais leves e facilmente acopláveis nos capacetes, botes, drones e da transmissão online e programação flexível de canais à cabo, assim como se dá com o surfe, segundo Damo (2006), a constituição de um público, mídia especializada e mercado profissional são processos fulcrais à existência do esporte espetáculo. O autor afirma que é necessário um trabalho sistemático, intensivo e duradouro de mediação entre a equipe e a nação para que uma modalidade "caia nas graças do povo".

Damo (2006) demonstra como a significância do futebol brasileiro, ao contrário da hipótese naturalista difundida pelo senso comum, foi investimento de mais de um século, reforçado pela priorização do futebol na ditadura militar, como importante estratégia política. Adicionalmente, Francischini (2009) demonstra como a nacionalização do futebol foi alavancada, contestando o senso comum da paixão espontânea, porque as elites políticas e empreiteiras estavam interessadas em sua expansão para lucro próprio, por suas posições de dirigentes clubísticos e seu interesse na construção de estádios.

Como o esporte incentivado no Brasil é majoritariamente aquele que traz retorno financeiro para a inciativa privada e não o esporte de participação como direito de todo o cidadão, nesta conjuntura se dá outra polêmica do processo de incorporação das práticas de aventura pelo esporte competitivo de alto rendimento. Ao passo que pretendem meIhores condições de prática para si, estes atletas promovem o esporte e trabalham por seu reconhecimento via massificação. Entretanto, a lotação dos ambientes naturais propícios para praticá-los é uma consequência incômoda, que pode gerar conflitos entre grupos, assim como verificado no surfe por Bandeira (2014), pois não permite a fruição daquele lugar ou fenômeno natural com a tão almejada liberdade, relatada pela literatura como um dos valores centrais nos esportes de aventura, e também aumenta o impacto ambiental, o que aparece como preocupação entre os pesquisados.

Retomando a discussão sobre a relação do rafting com a mídia, a maioria das notícias sobre as vitórias da equipe são da imprensa local. Quando em campeonato internacional, desfile em carro de bombeiros é oferecido pela prefeitura, no primeiro campeonato mundial conquistado uma placa de homenagem foi inaugurada pela prefeitura no Parque dos Saltos, que cruza o centro da cidade e é um dos locais de treinos da equipe. Pequenas notas saem em algum programa de alcance nacional. Diferentemente da expectativa que os atletas criaram, mesmo com o mundial acontecendo no Brasil, em Foz do Iguaçu, e sendo transmitido ao vivo por um canal esportivo de televisão a cabo em 2014, pouquíssimas reportagens, em sua maioria notas pontuais, aconteciam em mídia aberta de alcance nacional.

Adicionalmente à dificuldade com patrocínio pela baixa divulgação na mídia, os atletas da equipe ainda referem dificuldade em redigir pedidos de apoio e entender os trâmites de contratos de patrocínio e bolsas. Nesse sentido, o próximo excerto de entrevista leva a pensar mais uma questão conceitual: a impossibilidade de classificar esportes rigidamente em olímpicos, tomados como convencionais, e não olímpicos, tomados como alternativos: 
a gente já tá sem de novo. Já foi a papelada, mas a gente nem sabe se vão renovar. Ano passado só saiu a aprovação em Maio, a gente ficou cinco meses sem bolsa. Isso é sempre uma interrogação. Antes do mundial do ano passado, tinha dia que a gente chegava no rio com a roupa de treinar e tinha que sair de lá cada um pra um lado correndo atrás de dinheiro, porque se não tivesse o dinheiro pra chegar no campeonato, de que adiantava treinar? A gente não treinou tanto quanto devia, por causa disso, e ainda tem gente que cobra que a gente não conseguiu o tricampeonato. E isso por quê? Porque, além da bolsa que tá em espera, os dois únicos patrocinadores grandes que a gente conseguiu ter, a Mahle e a Itaipu, uma teve uma crise no Brasil e nos largou e a outra mudou a presidência e largou porque disse que ia focar a canoagem olímpica. E, por exemplo, o [1], é um cara que se dedica integralmente à equipe, se deixar ele faz coisa pra equipe dia e noite. E não tem dinheiro de família, sem a bolsa o que ele vai fazer? Ele vai precisar deixar a equipe de lado pra poder arrumar como comer, pagar as contas. E eu sofro por ele. Porque não é como muitos no Brasil que têm a bolsa e treina duas vezes por semana, uma horinha por dia. Você vê ele no rio sete da manhã treinando com a gente, as nove saindo pra descer com cliente, as duas da tarde treinando a molecada, as sete da noite com a gente de novo e depois desce rio de manhã e de tarde no fim de semana e no domingo à noite ensina as meninas. O rafting dele não é só pra ele. Isso é o que mais chateia, que mais indigna [...] E tudo porque o rafting não é um esporte olímpico. Por isso a gente tá tentando que vire modalidade de demonstração no Rio em 2016 (RAFTEIRO 4).

O Bolsa Atleta é um programa de patrocínio individual e direto a esportistas do Ministério do Esporte lançado em 2005. A remuneração para modalidades não olímpicas, na categoria atleta nacional era, na época, setecentos e cinquenta reais e para atleta internacional mil e quinhentos reais. Nas modalidades olímpicas era dois mil e quinhentos reais. Note a diferença de valores entre esportes olímpicos e não olímpicos e o olimpismo como vontade do atleta.

Além disto, este trecho de entrevista está diretamente relacionado ao fato de que alguns atletas entre a inscrição, concessão e início da vigência da Bolsa Atleta não conseguiam se manter em suas modalidades, mais um testemunho que expõe a fragilidade da situação de inclusão dos entrevistados nesta prática via esporte espetáculo. Apesar de ter sido vista pelos componentes da Bozo D’água, como uma evolução para o esporte, o trâmite da Bolsa Atleta não resolvia definitivamente a situação de instabilidade financeira da equipe. Estes tipos de situação levaram a CBCa a emitir a seguinte circular em 2011:

a Confederação Brasileira de Canoagem - CBCa recebeu do Ministério do Esporte a informação de que aproximadamente 200 atletas foram agraciados pelo Programa Bolsa Atleta, sendo uma das modalidades mais beneficiadas neste quesito pelo Governo Federal. Atletas de categorias olímpicas e não olímpicas poderão a partir de 2011 dedicarem-se exclusivamente aos treinamentos graças a este benefício. Ocorre, todavia, que o sistema empregado para as ações promovidas com verbas públicas necessita de cautela e rigor no empreendimento e isso às vezes pode causar constrangimentos face à morosidade e gerar equívocos. $\mathrm{O}$ atleta para conquistar o direito deverá obter os resultados previstos em lei para no ano seguinte poder solicitar as benesses do Bolsa-atleta. Caso seja contemplado, o atleta começará a receber o auxílio dois anos após a conquista. Esse ínterim de aproximadamente 
24 meses entre a conquista dos resultados que assegurará o direito ao Programa e o efetivo recebimento do auxílio financeiro, tem gerado certo desconforto ao Governo Federal e aos próprios atletas, pois muitos, por inúmeros motivos, deixam de praticar a modalidade, gerando fato impeditivo ao percebimento face ao completo descompasso entre o escopo precípuo almejado no Programa e a real situação de "ex-atleta". Infelizmente, por falta de valores em sua formação, muitos ex-atletas deixam de informar ao Governo Federal a sua real situação colocando em risco todo o Programa que atualmente pode ser considerado como o maior auxílio governamental de todos os tempos empregado diretamente aos atletas. Por esse motivo, a Confederação Brasileira de Canoagem preocupada com a assiduidade nos treinamentos dos atletas contemplados e devidamente cadastrados, vem, respeitosamente, solicitar dignem-se as filiadas de informar a cada dois meses, através de relatório repassados para o e-mail, a real situação do canoísta apresentando também o seu respectivo plano de treino. Caso isso não aconteça, a CBCa reserva-se ao direito de não fornecer certidões para o ano de 2012 às Entidades filiadas e Atletas cadastrados que não cumprirem com o dever legal de fiscalização do Programa Bolsa Atleta (Disponível em: http://www.canoagem.org.br/arquivos/ documentos/199-circular_0212011__termo_de_compromisso_filiadas_bolsa_atleta-14-4-2011-15-35-25.pdff).

Destacado no grifo, veja que a CBCa interpreta como um problema apenas de caráter a impossibilidade de manutenção do treinamento, ignorando as dificuldades vividas pelos atletas de classes baixas no país. Outro problema que afetava a Bozo D 'água era que a Bolsa Atleta só era concedida individualmente e não por equipe, para aqueles que conquistavam os primeiros lugares no pódio como titulares. Ou seja, se eles se machucavam ou estavam impossibilitados de competir no campeonato seguinte, quase sempre por compromissos em suas outras profissões, o substituto tinha que acompanhar toda a preparação da equipe sem a bolsa, ou ser incorporado às pressas. Estes fatores, além da diferença de valores e a falta de patrocinadores levavam os rafteiros de Brotas a desejarem que seu esporte se tornasse olímpico, mesmo que essas competições deixassem de acontecer na natureza, para acontecer em corredeiras artificiais, como em muitas provas de canoagem slalom, e que aconteceu no mundial de 2016 nos Emirados Árabes.

\section{CONSIDERAÇÕES FINAIS}

Apesar de terem conseguido construir para si uma rede de contatos e apoiadores que hoje permite uma situação menos vulnerável, os atletas da Bozo D 'água, agora hexacampeões mundiais, ainda se sentem desprezados pelo país que tanto lutam por representar. Embora haja "rafteiros" que operam deliberadamente valores distintos do olimpismo e a relação com a natureza e com o risco seja referida como motivação principal para adesão ao rafting, certos perfis de praticantes operam combinações entre categorias. A profissionalização esportiva, a competição (com vitória) e a representação nacional também são basilares para estes atletas da aventura que precisam do pódio para continuar praticando e, acreditam eles, necessitam que a modalidade se torne olímpica para que 
tenham melhor estrutura e estabilidade. Após a incorporação do surfe, da escalada e do skate pelos Jogos Olímpicos, anunciada em 2016, a definição de esportes de aventura como esportes não olímpicos deve ser superada e dar lugar à complexidade das inúmeras tensões e negociações que influenciam a conformação das diferentes modalidades.

Se tomarmos a Antropologia do Esporte como uma antropologia de nós mesmos e esta como oportunidade de reflexão crítica sobre nossas sociedades, temos no presente artigo mais uma perspectiva crítica do nacionalismo esportivo e da política de privilégio ao esporte de alto rendimento no Brasil. Nossas sociedades incitam os jovens a se tornarem atletas competitivos, mas correspondem as expectativas de ascensão social de pouquíssimos. No caso das atividades de aventura, ao invés de políticas públicas de democratização de acesso e incentivo a práticas de lazer que poderiam colocar e/ou manter em circulação valores diferentes daqueles já identificados como problemáticos no esporte convencional, tais como dopagem, machismo, construção de arenas excessivamente especializadas e grandes sem incorporação pela dinâmica das cidades sede dos megaeventos, entre outros, o que ainda vemos com maior intensidade é a institucionalização, a competição e o olimpismo incorporando modalidades que considerávamos alternativas a ele.

Embora a CBCa nos últimos anos tenha conferido status de seleção brasileira e oferecido uniformes iguais aos das seleções olímpicas de canoagem e auxílio financeiro aos atletas das equipes campeãs brasileiras de rafting para a participação no mundial, as dinâmicas informais e instáveis de prática e trabalho levaram a rupturas entre alguns membros de uma mesma equipe ou entre equipes originárias e sucessoras da Bozo D 'água que se reformularam. Além disto, em 2017 foi anunciado que o rafting deixará a CBCa para criar entidade de representação própria, o que inaugura um novo ciclo, tanto local quanto nacionalmente, e merece análise futura.

\section{REFERÊNCIAS}

ARCHETTI, Eduardo. El potrero, la pista y el ring: las patrias del deporte argentino. Buenos Aires: Colección Popular, 2001.

BANDEIRA, Marília. No galejo da remada: estudo etnográfico sobre a noção de aventura em Brotas, SP. 2012. 195 f. Dissertação (Mestrado) - Curso de Antropologia Social, Universidade Federal de São Carlos, São Carlos, 2012.

BANDEIRA, Marília; RIBEIRO, Olívia. Sobre os profissionais da aventura: problemas da atuação na interface esporte e turismo. Licere, Belo Horizonte, v. 18, n. 3, p.116-157, set. 2015.

BANDEIRA, Marília. Territorial disputes, identity conflicts, and violence in surfing. Motriz: Revista de Educação Física, Rio Claro, v. 20, n. 1, p.16-25, jan. 2014.

BANDEIRA, Marília. Políticas públicas para o lazer de aventura: entre esporte e turismo, fomento e controle do risco. 2016. 240 f. Tese (Doutorado) - Curso de Educação Física, Universidade Estadual de Campinas, Campinas, 2016. 
BETRÁN, Javier. Rumo a um novo conceito de ócio ativo e turismo na Espanha: atividades físicas de aventura na natureza. In: MARINHO, Alcyane; BRUHNS, Heloísa. Turismo, lazer e natureza. Barueri: Manole, 2003. p. 157-202.

BOURDIEU, Pierre. Como é possível ser esportivo? In: BOURDIEU, Pierre. Questões de Sociologia. Rio de Janeiro: Marco Zero, 1983. p. 136-163.

BOURDIEU, Pierre. Programa para uma sociologia do esporte. In: BOURDIEU, Pierre. Coisas Ditas. São Paulo: Brasiliense, 1990. p. 207-220.

BRACHT, Valter. Sociologia crítica do esporte: uma introdução. Ijuí: Unijuí, 2005.

CARNICELLI FILHO, Sandro; SCHWARTZ, Gisele. Guias de Rafting: perfil e emoções. Lécturas Educación Física y Deportes, Buenos Aires, v. 10, n. 85, p.01-02, jun. 2005. CLIFFORD, James. A experiência etnográfica: Antropologia e Literatura no Século XX. Rio de Janeiro: Edufrj, 2002.

COSTA, Vera Lucia. Esportes de aventura e risco na montanha: um mergulho no imaginário. Barueri: Manole, 2001.

DAMO, Arlei. Do dom à profissão: uma etnografia do futebol de espetáculo a partir da formação de futebolistas no Brasil e na França. 2002. 435 f. Tese (Doutorado) - Curso de Antropologia Social, Universidade Federal do Rio Grande do Sul, Porto Alegre, 2006.

DIAS, Cleber; MELO, Victor Andrade de; ALVES JUNIOR, Edmundo. Os estudos dos esportes na natureza: desafios teóricos e conceituais. Rev. Port. Cien. Desp, Porto, v. 3, n. 7, p.358-367, dez. 2007.

FRANCISCHINI, Sandro. A difícil nacionalização do futebol brasileiro: a era Havelange. In: TOLEDO, Luiz Henrique de; COSTA, Carlos Eduardo. Visão de jogo: antropologia das práticas esportivas. São Paulo: Terceiro Nome, 2009. p. 167-195.

GEERTZ, Clifford. A interpretação das culturas. Rio de Janeiro: Ltc, 1989.

LACROIX, Michel. O culto da emoção. Rio de Janeiro: José Olympio, 2006.

BRETON, David Le. Condutas de risco: dos jogos de morte ao jogo de viver. Campinas: Autores Associados, 2009.

MARINHO, Alcyane. Da aceleração ao pânico de não fazer nada: corpos aventureiros como possibilidade de resistência. In: MARINHO, Alcyane; BRUHNS, Heloísa. Turismo, lazer e natureza. Barueri: Manole, 2003. p. 29-52.

MARINHO, Alcyane. Lazer, Aventura e Risco: reflexões sobre atividades realizadas na natureza. Movimento, Porto Alegre, v. 14, n. 2, p.181-206, maio 2008.

MASCARENHAS, Fernando. Megaeventos esportivos e Educação Física: alerta de tsunami. Movimento, Porto Alegre, v. 18, n. 1, p.39-67, jan. 2012.

PEREIRA, Dimitri; ARMBRUST, Igor; RICARDO, Denis. Esportes radicais de aventura e ação, conceitos, classificações e características. Corpoconsciência, Santo André, v. 12, n. 1, p.37-55, jan. 2008.

PIMENTEL, Giuliano. Ritos e risco na prática do voo livre. Movimento, Porto Alegre, v. 14, n. 3, p.13-32, set. 2008.

PIMENTEL, Giuliano. Esportes na natureza e atividades de aventura: uma terminologia aporética. Revista Brasileira de Ciências do Esporte, Florianópolis, v. 35, n. 3, p.687700, jul. 2013. 
POCIELLO, Christian. Os desafios da leveza: as práticas corporais em mutação. In: SANT'ANNA, Denise. Políticas do Corpo. São Paulo: Estação Liberdade, 1995. p. 115-120.

RINEHART, Robert; SYDNOR, Synthia. To The Extreme: alternative sports inside and out. Albany: State University Of New York Press, 2003.

SÁ, Mario; BRANDÃO, Leonardo. Esportes Radicais: Indícios de uma nova sociedade internacional em um mundo globalizado?. Revista Esporte e Sociedade, Niterói, n. 11, p.25-41, mar. 2009.

SCHWARTZ, Gisele. Aventuras na natureza: consolidando significados. Jundiaí: Fontoura, 2006.

SCHWARTZ, Gisele; CARNICELLI FILHO, Sandro. (Desin)Formação profissional e atividades de aventura: focalizando os guias de "Rafting". Rev. Bras. Educ. Fís. Esp, São Paulo, v. 20, n. 2, p.103-109, abr. 2006.

SOUSA, Fabiana. O imaginário no rafting: uma busca pelos sentidos da aventura, do risco e da vertigem. São Paulo: Zouk, 2004.

SPINK, Mary Jane. Posicionando pessoas como aventureiros potenciais: imagens de riscoaventura em matérias de revista. Psicologia \& Sociedade, Edição Especial, p.50-60, 2008.

STIGGER, Marco Paulo. Esporte, lazer e estilos de vida. Campinas: Autores Associados, 2002.

TOMLINSON, Alan et al. Lifestyle sports and national sport policy: an agenda for research. Londres: Report to Sporte England, 2005.

UVINHA, Ricardo. Juventude, lazer e esportes radicais. São Paulo: Manole, 2001.

WACQUANT, Loic. Corpo e alma: notas etnográficas de um aprendiz de boxe. Rio de Janeiro: Relume Dumará, 2002.

WHEATON, Belinda. Understanding lifestyle sports. Londres: Routledge, 2004.

WHEATON, Belinda. The cultural politics of lifestyle sports. Londres: Routledge, 2013.

Recebido em: Julho/2017

Aprovado em: Novembro/2017 